\title{
Implementation of the agricultural university educational programs during a pandemic: participants' opinions
}

\author{
Ludmila Filimonyuk ${ }^{1}$, Valentine Ivashova ${ }^{2, *}$, Victoria Burlyaeva ${ }^{3}$, Elena Sorokina $^{3}$, and \\ Elena Litvinova ${ }^{3}$ \\ ${ }^{1}$ North Caucasus Federal University, 1, Pushkin Street, Stavropol, 355017, Russia \\ ${ }^{2}$ Stavropol State Agrarian University, 12, Zootekhnichesky Lane, Stavropol, 355017, Russia \\ ${ }^{3}$ Nevinnomyssk State Humanitarian and Technical Institute, 11, Gagarin Street, Nevinnomyssk, \\ 357108, Russia
}

\begin{abstract}
The article presents the results of a study of the opinions of students and teachers of the southern region of Russia about the learning process in higher education programs during the COVID-19 pandemic. We carried out a comparative analysis of the quality of the implementation of educational programs in the assessments of participants in the process during the onset of the COVID-19 pandemic (April-May 2020) and its peak values (November-December 2020). The positive and negative consequences of transferring training to a distance learning format are formulated. Among the positive consequences are: the availability of training from anywhere; more flexible training, focused on the educational needs of students; new formats of social student life; more accessible communication with teachers. We analyzed the experience of the educational community presented in publications during the COVID-19 pandemic. The data obtained provide an understanding of the importance of the development and implementation of new organizational and methodological approaches for the effective response of higher education to external global challenges of our time.
\end{abstract}

\section{Introduction}

The work of the education system around the world in 2020 faced a global challenge the COVID-19 pandemic, which led to the urgent need to look for opportunities to continue the learning process. One issue was the switch-over of classes at all levels of education, except for preschool, into a distance format $[1,2]$. Modern development of technical means of communication, the level of development of teaching competencies in the field of information technology, technical equipment of the overwhelming majority of Russian universities made it possible to pass this stage quite painlessly and practically without prejudice to the quality of education $[3,4,5]$. At the same time, the issue of developing feedback with participants in the educational process for timely informing the organizers

\footnotetext{
*Corresponding author: vivashov@mail.ru
} 
about emerging situations and problems in order to eliminate them has received great urgency $[6,7]$.

\section{Materials and methods}

An empirical study of the implementation of educational programs of a university during a pandemic was carried out using the method of electronic questionnaire in Google Form. Students and professors of universities in the South of Russia are involved in the survey. To conduct a comparative analysis of the quality of implementation of university educational programs during the onset of the COVID-19 pandemic (April-May 2020) and its peak values (November-December 2020), only 824 students (407 and 416 people, respectively) and 257 university teacher (126 and 131 people, respectively).

Statistical distributions were performed using SPSS Statistics (version 21). Instrumentation for researching teachers' opinions included 19 questions, students' opinions -23 questions. The questions are presented by informational and thematic sections of the questionnaires, which generally describe the process of implementation of university educational programs in terms of content, material, technical and educational and methodological security, assessing the possibility of forming general cultural and professional competencies.

\section{Results}

During the transition to distance learning from April 2020, it was necessary to adapt the entire supporting complex of the educational process of university education. It should be noted that there were no critical problems jeopardizing the quality of the educational process. Each of the comments made related to the sphere of influence of universities, on average, does not exceed $35 \%$ of the threshold.

Among the difficulties in organizing lectures, which are named by teachers, the most relevant are: unsatisfactory quality of the Internet $(34.6 \%$ - teachers came to classes from home Internet access); the need to use personal computer equipment $(28.5 \%$ and we are talking about lower technical characteristics of home equipment compared to university and the need for distance learning for their own children, remote work of family members, which increased the load on equipment and Internet traffic); insufficient technical characteristics of computer equipment, including students $(19.9 \%)$; transformation of material for presentation into material in a remote format $(19.2 \%)$; a significant increase in the volume of information (16.2\%); lack of distance communication skills (11.9\%). 36.3\% noted that there were no difficulties.

Among the difficulties that are named in order of importance in organizing and conducting practical classes, the most urgent is the difficulty of forming the skills and abilities of students in a distance format (49.5\%). Further, there are such difficulties as: checking tasks in a remote format takes time that goes beyond the working day $(36.5 \%)$; a significant increase in the amount of information and time for interaction with students (30.5\%); poor internet performance $(29.9 \%)$; the need to use personal computer equipment $(21.8 \%)$; insufficient technical characteristics of computer technology for practical training (17.7\%). $22.2 \%$ of the survey participants noted that there were no difficulties.

Among the main difficulties in carrying out the current academic assessment of students were named: the lack of technical ability of a number of students to send completed assignments in a timely manner $(66.0 \%)$; difficulties with attaching completed tasks to the EEEP (28.1\%); multiple electronic interaction for high-quality task performance $(27.6 \%)$. 
$25.8 \%$ of the survey participants said that there were no difficulties during the current academic assessment.

Thus, the main problem points in the organization of distance learning are the lack of technical ability for a number of students to send completed tasks in a timely manner; the difficulty of forming the skills and abilities of students in a distance format; checking tasks in a remote format takes time that goes beyond the working day; a significant increase in the amount of information and time for interaction with students; poor internet performance.

The technical support service of the educational process at the university during the period of distance learning worked, in the opinion of the teaching staff who took part in the survey, on average by 7.5 points on a ten-point scale. According to the teachers' assessments, the most problematic was the situation in biotechnology and engineering programs.

Based on the experience gained during the period of work in a remote mode, $43.8 \%$ of the teaching staff noted that for lectures, a third of distance learning and two-thirds of contact learning would be the optimal combination. 19.1\% of survey participants believe that for lectures it is possible to transfer two-thirds to a distance format, and give one-third of the total number of lecture hours in a contact form. $25.5 \%$ expressed the opinion that the hours allocated for lectures in the curriculum should be equally spent in a distance and contact format. $11.6 \%$ believe that all lectures should be conducted in contact mode.

The distribution of opinions regarding the possibilities of high-quality practical training in the distance format is even more pronounced towards contact training:

$-58.0 \%$ indicated the desired ratio - a third of distance learning and two-thirds of contact training; $-22.7 \%$ - contact training only;

$-14.5 \%$ - half of the contact and half of the distance learning;

- only $4.8 \%$ noted that two-thirds of practical classes can be held in distance mode and a third - in contact.

The survey participants generally reacted positively to the opportunity to receive support from employers on the basis of a contract and subsequent employment: $52.8 \%$ of students noted the option "positive", the option "rather positive" was noted by $30.0 \%$ of students. Rather than $4.3 \%$ and $1.6 \%$ of students reacted negatively to such an initiative, respectively. Only $11.2 \%$ of the survey participants could not give a definite answer.

Almost half of the students support the proposal to reduce the duration of study in basic professional educational programs: the option "positive" was noted by $23.7 \%$ of students, the option "rather positive" was noted by $32.9 \%$ of students. Rather than $10.3 \%$ and $13.1 \%$ of students reacted negatively to such an initiative, respectively. $20.0 \%$ of the survey participants could not give a definite answer.

About $60 \%$ of the survey participants noted their positive attitude to the proposal to study modules of other faculties and universities within one educational program: the option "positive" was noted by $23.4 \%$ of students, the option "rather positive" was noted by $37.8 \%$ of students. Rather than $18.2 \%$ and $6.8 \%$ of students reacted negatively to such an initiative, respectively. $13.8 \%$ of survey participants could not give a definite answer.

During the survey, students showed their understanding of the importance of opportunities to engage in research work during their studies at the university. $88.8 \%$ of survey participants believe that SSRP (student scientific research project) should be done at will. An insignificant share of respondents $(0.8 \%)$ believes that SSRP should be compulsory for every student; $3.4 \%$ of survey participants believe that students should not engage in this activity; $7.0 \%$ - could not give a definite answer.

According to students, the three main factors that employers pay attention to are the experience of undergoing internships and internships at specialized enterprises within the framework of the main educational program (noted by $63.1 \%$ of students); level of 
education (noted by $40.5 \%$ of students); the presence of specialized skills obtained in the framework of additional education and the level of the mastered educational program (skilled workers, secondary vocational education, Bachelor's Degree, Specialist's Degree, Master's Degree) (noted by $35.7 \%$ and $35.3 \%$, respectively).

In the opinion of almost a third of the survey participants $(34.5 \%)$, the quality of education has not changed due to the transfer to the distance format. The quality of education has improved according to $19.9 \%$ of students. The quality has deteriorated in the opinion of $37.6 \%$. And $7.6 \%$ of respondents found it difficult to give a definite assessment. Students saw the pros and cons of distance learning. The main advantages are:

- accessibility of training from any place (noted by $79.1 \%$ of respondents);

- training has become more flexible and focused on their educational needs (noted by $29.5 \%$ of respondents);

- new formats of social student life have appeared (noted by $20.0 \%$ of respondents);

- communication with professors has become more accessible (noted by $15.8 \%$ of respondents).

The data are presented in Table 1 and shown in segmentation by economic and biotechnological programs.

Table 1. Opinions of students of economic and biotechnology programs of the university on the merits of distance learning during a pandemic (\%).

\begin{tabular}{|l|c|c|c|}
\hline \multicolumn{1}{|c|}{ Answer options } & $\begin{array}{c}\text { Economic } \\
\text { programs }\end{array}$ & $\begin{array}{c}\text { Biotechnological } \\
\text { programs }\end{array}$ & Total \\
\hline 1. Accessibility of training from anywhere & 86.8 & 71.4 & $\mathbf{7 9 . 1}$ \\
\hline $\begin{array}{l}\text { 2. Training materials have become more diverse, } \\
\text { access to courses from other educational } \\
\text { organizations has appeared }\end{array}$ & 14.7 & 28.6 & $\mathbf{2 1 . 6}$ \\
\hline $\begin{array}{l}\text { 3. Education has become more flexible and } \\
\text { focused on my educational needs }\end{array}$ & 33.8 & 25.1 & $\mathbf{2 9 . 5}$ \\
\hline $\begin{array}{l}\text { 4. Communication with teachers has become } \\
\text { more accessible }\end{array}$ & 10.3 & 21.4 & $\mathbf{1 5 . 8}$ \\
\hline $\begin{array}{l}\text { 5. There is more freedom in the choice of } \\
\text { practical (laboratory, research, project, creative, } \\
\text { etc.) classes }\end{array}$ & 20.6 & 3.6 & $\mathbf{1 2 . 1}$ \\
\hline $\begin{array}{l}\text { 6. New formats of social student life have } \\
\text { appeared }\end{array}$ & 22.1 & 17.9 & $\mathbf{2 0 . 0}$ \\
\hline 7. It is difficult to answer & 8.8 & 14.3 & $\mathbf{1 1 . 6}$ \\
\hline
\end{tabular}

Among the negative effects of distance learning were named:

- problems with hardware and software (noted by $61.2 \%$ of respondents);

- lack of communication with fellow students (noted by $44.6 \%$ of respondents);

- difficult assimilation of the material during independent study (noted by $34.4 \%$ of respondents);

- communication with professors has become more difficult (noted by $29.8 \%$ of respondents).

- limited opportunities for practical and laboratory lessons remotely (noted by $29.6 \%$ of respondents).

\section{Discussion}

The discussion, unfolded in the educational community, both in Russia and in the world, shows the social and educational practices of overcoming the difficulties of implementing educational programs, including higher education, in a remote format. 
The authors of the study R. Scherer, S.K. Howard, J. Tondeur, F. Siddiq analyzed the success of the transition to university online learning in the framework of an international survey [8]. The study found that the teaching community is not homogeneous in its characteristics, which influence the quality of the transition to online learning. Three profiles of teachers were identified: with consistently high, consistently low training and an inconsistent profile of readiness. An important substantive conclusion of the authors, which concerns the latent factors of readiness for online teaching, is that the key factors are the innovative potential in education and the cultural orientation of the individual. Thus, in the teaching community, it is important to promote ideas of openness to new things, breadth of cultural views and readiness to adapt to changing conditions.

L.D. Lapitan, C.E. Tiangco, D.A. Sumalinog, N.S. Sabarillo, J.M. Diaz share their positive experiences in overcoming the difficulties of the transition to online learning, which is especially difficult to implement for engineering, biochemical and other technological disciplines [9]. Researchers, based on the analysis of teaching and learning in a remote format, consider the conclusions based on 3 indicators to be valid: the student's learning experience, the student's progress and the teacher's observations. In the course of studying the problems of implementing university educational programs, the following were named: the stability of the Internet for all participants in the educational process and the level of training of the teacher in the field of software for video conferencing. The authors in the study raise an important question - maintaining educational motivation in the classroom and activating the process of perceiving information in the online format.

The isolation measures taken during the pandemic, including for the implementation of university educational programs, had a significant impact on students. Quarantine and social distancing affected students, including negatively affected the mental well-being of students, as noted by the authors G.M. Baloch, S. Sundarasen, K. Chinna, S.F.A. Hossain, A. Al Sukayt [10]. Online education changes the quality of the content of social communication, rightly actualizes the issue of psychological support for students.

The scientific discussion that goes on regarding the consequences of distance learning at university touches on both the positive and negative consequences of this situation. In a longitudinal study that was conducted at German universities and generally covered the period of the onset and peak of the pandemic, students named flexibility over time and the use of new information technologies in the educational process as positive factors. The authors of the study G. Vladova, A. Ullrich, B. Bender, N. Gronau draw attention to the fact that among the significant disadvantages of online learning, students name social isolation, which in general significantly reduces the perceived usefulness of higher education [11].

Thus, the discussion developed in the scientific community shows the relevance of the topic raised and once again emphasizes the need to present positive practices for solving common problems of education and youth for a sustainable future. The development of virtual communities of teaching practitioners, to a certain extent, makes it possible to solve this problem. This is stated by $T$. McLaughlan in the article [12], summarizing the experience gained during the COVID-19 pandemic $[13,14,15,16]$.

\section{Conclusion}

Summing up the results of the student survey, a number of conclusions can be drawn regarding the organization and quality of implementation of university programs during the COVID-19 pandemic.

Firstly, it should be noted that the emergency transition to distance learning did not cause a collapse of university education, as evidenced by the results of sample studies conducted among students and teachers in the South of Russia. The implementation of 
educational programs was continued with an insignificant number of restrictions, which mainly concerned practical training and technical capabilities of students to work efficiently in a remote format.

Secondly, according to the comments in the organization of training in the first wave of the pandemic, measures were taken that made it possible to correct and prevent possible difficulties at the beginning of the academic year 2020-2021.

Thirdly, according to the students, the emergency transition to the distance learning format has also brought positive effects: the availability of learning from any place; training has become more flexible and focused on their educational needs; new formats of social student life have appeared; communication with teachers has become more accessible.

\section{References}

1. M. Gottschalk, K. Werwick, C. Albert, R.C. Philipp Stieger, GMS Journal for Medical Education 38(1), 1-8 (2021)

2. V. Levina, S. Zubanova, A. Ivanov, XLinguae 14(1), 212-227 (2021)

3. E.V. Frolova, O.V. Rogach, T.M. Ryabova, Perspektivy Nauki i Obrazovania 48(6), 78-88 (2020)

4. J. Izagirre-Olaizola, J. Morandeira-Arca, Sustainability (Switzerland) 12(23).10137, 118 (2020)

5. R. Allande-Cussó, Journal of Nursing Education 59(12), 709-713 (2020)

6. Z. Gardanova, V. Ponkratov, N. Kuznetsov, E. Latypova, S. Shcherbatykh, Journal of Open Innovation: Technology, Market, and Complexity 6(4).147, 1-21 (2020)

7. S. Welsen, M. Pike, J. Walker, 2020 IFEES World Engineering Education Forum Global Engineering Deans Council 9293649 (2020)

8. R. Scherer, S.K. Howard, J. Tondeur, F. Siddiq, Computers in Human Behavior 118, $106675(2021)$

9. L.D. Lapitan, C.E. Tiangco, D.A. Sumalinog, N.S. Sabarillo, J.M. Diaz, Education for Chemical Engineers 35, 116-131 (2021)

10. G.M. Baloch, S. Sundarasen, K. Chinna, S.F. Hossain, A. Al Sukayt, Peer J 9, 10612 (2021)

11. G. Vladova, A. Ullrich, B. Bender, N. Gronau, Frontiers in Psychology 12, 636086 (2021)

12. T. McLaughlan, International Journal of Information and Learning Technology 38(2), 177-195 (2021)

13. V. Bonavolontà, S. Cataldi, D. Maci, F. Fischetti, Communications in Computer and Information Science 1344, 151-157 (2021)

14. J. Kobylarczyk, D. Kuśnierz-Krupa, World Transactions on Engineering and Technology Education 19(1), 48-51 (2021)

15. J. Rojas-Mora, O.A. Herrera, P. Mirabal, M. Levano, Proceedings - International Conference of the Chilean Computer Science Society, SCCC 2020-November 9281214 (2020)

16. I. Baklanov, V. Rodionova, V. Ivashova, L. Shvachkina, V. Medvedeva, Quality Access to Success 21(179), 88-90 (2020) 